\title{
Using the Diffusion of Innovation Theory to Understand the Challenges and Opportunities to Advancing Use of Nutrigenetics in Clinical Practice
}

\author{
Olivia M. Dong ${ }^{\mathrm{a}, \mathrm{b}}$ \\ aDepartment of Medicine, Duke Center for Applied Genomics \& Precision Medicine, Duke University School of \\ Medicine, Durham, NC, USA; b Durham VA Health Care System, United States Department of Veterans Affairs, \\ Durham, NC, USA
}

\author{
Keywords \\ Genetics · Genomics · Nutrigenomics · Nutrition · Precision \\ nutrition
}

\section{Introduction}

The National Human Genome Research Institute (NHGRI) published bold predictions for genomic medicine to strive toward by 2030 [1]. These predictions outline a promising impact genomic information will have on health, including aspirations such as enabling individuals to securely access genome sequencing results on their smartphones and making the use of genomic information as routine in all clinical settings [1]. One application of genomic medicine is nutrigenetics (NGx), which investigates the associations between genetic variants, diet, and health outcomes [2]. NGx has the potential to use genetic information in ways that can further individualize nutrition interventions to help patients achieve improved health outcomes. While incorporating NGx testing as part of clinical care is promising, it is not routinely done in clinical settings. To better understand how NGx testing can strive toward routine use per NHGRI's aspirational

\begin{tabular}{ll}
\hline karger@karger.com & ( 2021 The Author(s) \\
www.karger.com/lfg & $\begin{array}{l}\text { Published by S. Karger AG, Basel } \\
\text { This is an Open Access article licensed under the Creative Commons }\end{array}$ \\
Karger & $\begin{array}{l}\text { Attribution-NonCommercial-4.0 International License (CC BY-NC) } \\
\text { (http://www.karger.com/Services/OpenAccessLicense), applicable to } \\
\text { the online version of the article only. Usage and distribution for com- } \\
\text { mercial purposes requires written permission. }\end{array}$
\end{tabular}

goals, the diffusion of innovation (DOI) theory will be used as a framework to examine the challenges and opportunities of integrating NGx testing into clinical care. The DOI theory seeks to explain the spread of innovations through populations and how they get adopted over time [3], with recognition that the majority of innovations fail to successfully diffuse through populations and that adoption is not necessarily based on the effectiveness of innovations [4]. In fact, effective innovations can be stalled, while ineffective innovations can sometimes diffuse farther in comparison [4]. The adoption rate for innovations relies on several factors, including the perceived attributes of the innovation, characteristics of the adopters, communication channels (e.g., mass media), and the social system (e.g., diffusion within health-care systems) [3]. The perceived attributes of NGx testing and characteristics of adopters will be discussed in more detail.

\section{Innovation Attributes}

Attributes of an innovation that impacts adoption are its perceived relative advantage, compatibility, complexity, trialability, and observability (Table 1). 
Table 1. Five perceived attributes of an innovation [3]

\begin{tabular}{|c|c|c|}
\hline Attribute & Definition & Association with adoption \\
\hline 1. Relative advantage & $\begin{array}{l}\text { The degree to which an innovation is perceived beneficial } \\
\text { (e.g., economic, convenience, and health outcomes) over } \\
\text { the action, idea, or product it is replacing }\end{array}$ & $\begin{array}{l}\text { The greater the perceived advantage, the more } \\
\text { rapid the innovation is likely to be adopted }\end{array}$ \\
\hline 2. Complexity & $\begin{array}{l}\text { The degree to which an innovation is perceived as } \\
\text { difficult to use or understand }\end{array}$ & $\begin{array}{l}\text { The greater the complexity, the less likely an } \\
\text { innovation is adopted }\end{array}$ \\
\hline 4. Trialability & $\begin{array}{l}\text { The degree to which an innovation can be experimented } \\
\text { with on a limited basis before adopting it more } \\
\text { permanently }\end{array}$ & $\begin{array}{l}\text { The greater the perceived trialability, the more } \\
\text { rapid the innovation is likely to be adopted }\end{array}$ \\
\hline 5. Observability & $\begin{array}{l}\text { The degree to which the results of an innovation are } \\
\text { tangible }\end{array}$ & $\begin{array}{l}\text { The greater the perceived observability, the more } \\
\text { rapid the innovation is likely to be adopted }\end{array}$ \\
\hline
\end{tabular}

\section{Relative Advantage}

Characterizing the relative advantage NGx testing provides patients is critical in justifying its integration into clinical practice. Despite randomized controlled trial data demonstrating that NGx testing is associated with improved health outcomes $[5,6], 1$ challenge to incorporating NGx testing more widely within clinical care is the lack of an established standardized evaluative process that provides recommendations on the clinical integration of specific gene-nutrient interactions. This standardized evaluative process would provide better transparency in the level of evidence needed for clinical integration and identify where gaps of evidence exist for each specific gene-nutrient interaction. The pharmacogenomic (PGx) field, which investigates the impact of genetic variability on drug response, has dealt with similar implementation challenges and has addressed this issue with an established framework evaluating the evidence level for integrating PGx testing for specific gene-drug pairs into clinical care (level A [genetic information should be used to change prescribing of affected drug] to $\mathrm{D}$ [genetic information not recommended to change prescribing of affected drug]) [7, 8]. This standardized evaluative framework is integrated into the evidence-based clinical practice guidelines for individual gene-drug pairs (e.g., CYP2C19 and clopidogrel) that are published, which has helped clinicians and researchers understand the advantage PGx testing for each gene-drug pair provides, as well as the level of evidence supporting its clinical implementation [8]. These guidelines have served as the basis for many clinical and research PGx testing initiatives $[9,10]$. A framework for evaluating evidence levels has been dis- cussed for NGx gene-nutrient interactions but has yet to be widely adopted [11]. Assessing evidence for specific gene-nutrient interactions is important since implementation of NGx testing will likely focus on specific genenutrient pairs as evidence changes. Improving how NGx findings are reported from research studies has also been recommended to increase the ability for findings to be translated into practice [12].

In addition, implementation strategies required for successful adoption of NGx testing into patient care in ways that lead to significant behavior change are also needed. Very little is known about these optimal implementation strategies as evidenced by the 2021 Academy of Nutrition and Dietetics (AND) consensus report results (i.e., insufficient evidence for whether there are effects of incorporating genetic testing into nutrition practice) [13], although personalized nutrition interventions (vs. generalized dietary recommendations) have been shown to improve dietary intake [14]. This gap in implementation knowledge also highlights the lack of funding in the translational space as $98 \%$ of human genomic research funding goes toward the discovery phase [15]. Implementation science investigates optimal integration of evidenced-based practices into real-world settings and can be integrated into studies to identify strategies that implement NGx-based interventions in ways that result in improved health outcomes [16-18].

Last, the health economics of health innovations is critical to quantify, given rising health-care costs and the need to use finite health-care resources efficiently. Although the concept of conducting cost-effectiveness analyses for health innovations was first introduced in 1977 


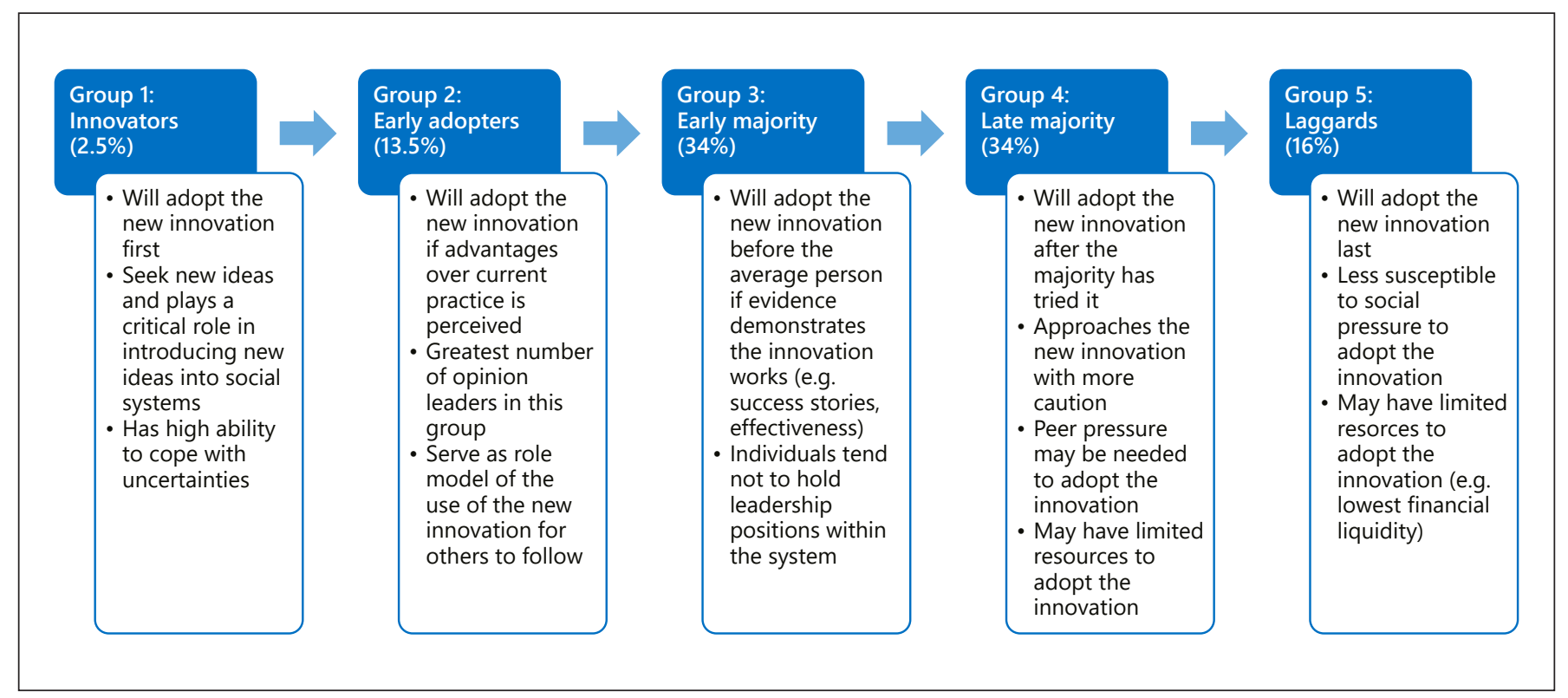

Fig. 1. Distinct groups adopting an innovation within a population $[3,4]$. Adoption of an innovation is thought to progress through a population first through innovators (2.5\% of the population), then through early adopters ( $13.5 \%$ of the population), then through the early majority ( $34 \%$ of the population), then through the late ma-

[19], it was not until recently that professional organizations proposed integrating cost-effectiveness/value assessments directly into clinical guidelines [20]. A recent systematic review evaluating the cost-effectiveness of personalized nutrition interventions did not find any studies that included genotype approaches [21]. Lack of economic studies can make it challenging to justify integrating NGx testing within patient care.

\section{Compatibility}

NGx information has the potential to provide more individualized nutrition recommendations and achieve better health outcomes, which is highly compatible with the care goals within dietetic practice. The AND's position article on nutritional genomics recognized the potential for NGx testing to improve patient care, although concluded that it is not ready for integration into routine practice yet [22]. Limiting genetic testing to specific, targeted NGx variants that have been well-studied and are associated with actionable steps that patients can take to achieve improved health outcomes compared to broad testing (e.g., whole genome sequencing) can minimize unintended consequences $[23,24]$, mitigate patients' fears around undergoing genetic testing, and increase the likelihood that NGx testing is adopted. jority (34\% of the population), and finally through the laggards (16\% of the population). Early adopter groups tend to have a higher ability to cope with risks and uncertainties associated with innovations than that of later groups, which have a higher need to be assured that success will result if the innovation is adopted.

\section{Complexity}

Registered dietitian nutritionists (RDNs) need proper NGx training to decrease the complexity of integrating NGx into dietetics practice. Nutritional genomics was recently added as a required competency for accredited US Didactic Programs in Dietetics to help address the low knowledge and confidence in using genetic testing in dietetics practice among RDNs [13]. The task of assessing the evidence for integrating NGx testing into clinical care has been placed on RDNs who oftentimes do not have the bandwidth to tackle this daunting process [25], increasing the complexity required for NGx to be adopted more widely. More resources that decrease the complexity of acquiring NGx competencies and translating research findings into practice will help improve the likelihood that NGx testing is incorporated into clinical care. To draw further on the successes from the PGx field, standardized genetic terminology has been established in the gene-drug guidelines, making it easier to report and interpret PGx results and allowing for consistency in the PGX implementation across health systems [26]. These PGx guidelines have overcome the lack of clinician training in PGx barrier by creating guidelines that focus on actionable steps that can be taken to incorporate genetic test results into practice. 
Trialability and Observability

The trialability and observability attributes are important in the rate of adoption for NGx testing, especially when there is better establishment of the strength of evidence for gene-nutrient interactions. The extent that health systems can trial different methods of rolling out NGx testing and the associated resources to help with the implementation process (e.g., clinical decision support tools and training) in the future to find the optimal strategy will allow for individualization that may lead to better adoption. Ensuring tangible benefits are captured through data collection methods to demonstrate that health outcomes are being impacted by NGx testing can also accelerate the adoption of the innovation.

\section{Adopter Characteristics}

The DOI theory outlines 5 distinct adopter groups within a social system based on their attitude toward innovations and their threshold for adapting to change (Fig. 1). It is important to recognize the unique information and resources each group requires in order to adopt NGx testing. Adopter groups with more flexibility and resources to support NGx testing can help gather data that later adopter groups with less resources and ability to deal with uncertainties seek out before adopting NGx testing.

\section{Conclusion}

NGx testing is a promising application of genomic medicine with potential to improve patient care. While NGx testing is far from routine clinical use, concrete steps can be taken to ensure this health innovation diffuses successfully within the population. Of the perceived attributes that were discussed for NGx testing, characterizing the relative advantage and decreasing the complexity to its use clinically will be key. In addition, addressing the needs of distinct adopter groups within a population might accelerate its adoption over time.

\section{Conflict of Interest Statement}

The author has no conflicts of interest to declare.

\section{Funding Sources}

O. Dong was supported by the National Human Genome Research Institute (NHGRI) of the National Institutes of Health (NIH) under Award No. 5T32HG008955-03. The content is solely the responsibility of the author and does not necessarily represent the official views of the NIH or the US Department of Veterans Affairs.

\section{Author Contributions}

O.M.D. conceptualized and wrote this article.

\section{References}

1 Green ED, Gunter C, Biesecker LG, Di Francesco V, Easter CL, Feingold EA, et al. Strategic vision for improving human health at The Forefront of Genomics. Nature. 2020 Oct; 586(7831):683-92.

2 Fenech M, El-Sohemy A, Cahill L, Ferguson LR, French TA, Tai ES, et al. Nutrigenetics and nutrigenomics: viewpoints on the current status and applications in nutrition research and practice. J Nutrigenet Nutrigenomics. 2011;4(2):69-89.

3 Rogers EM. Diffusion of innovations. 4th ed. New York, NY: Free Press; 1995.

4 Dearing JW, Cox JG. Diffusion of innovations theory, principles, and practice. Health Aff. 2018 Feb;37(2):183-90.

5 Nielsen DE, El-Sohemy A. Disclosure of genetic information and change in dietary intake: a randomized controlled trial. PLoS One. 2014;9(11):e112665.

6 Horne J, Gilliland J, O’Connor C, Seabrook J, Madill J. Enhanced long-term dietary change and adherence in a nutrigenomics-guided lifestyle intervention compared to a population-based (GLB/DPP) lifestyle intervention for weight management: results from the NOW randomised controlled trial. BMJ Nutr Prev Health. 2020;3(1):49-59.

7 CPIC: Clinical Pharmacogenetics Implementation Consortium. June 8, 2021. July 10, 2021.

8 Caudle KE, Klein TE, Hoffman JM, Muller DJ, Whirl-Carrillo M, Gong L, et al. Incorporation of pharmacogenomics into routine clinical practice: the clinical pharmacogenetics implementation consortium (CPIC) guideline development process. Curr Drug Metab. 2014 Feb;15(2):209-17.

9 van der Wouden $\mathrm{CH}$, Cambon-Thomsen A, Cecchin E, Cheung KC, Dávila-Fajardo CL, Deneer $\mathrm{VH}$, et al. Implementing pharmacogenomics in Europe: design and implementation strategy of the ubiquitous pharmacogenomics consortium. Clin Pharmacol Ther. 2017 Mar; 101(3):341-58.

10 Dong OM, Bates J, Chanfreau-Coffinier C, Naglich M, Kelley MJ, Meyer LJ, et al. Veterans affairs pharmacogenomic testing for veterans (PHASER) clinical program. Pharmacogenomics. 2021 Jan 6;22:137-44.
11 Grimaldi KA, van Ommen B, Ordovas JM, Parnell LD, Mathers JC, Bendik I, et al. Proposed guidelines to evaluate scientific validity and evidence for genotype-based dietary advice. Genes Nutr. 2017;12:35.

12 Horne JR. Strengthening the reporting of nutritional genomics research to inform knowledge translation in personalized nutrition. Lifestyle Genom. 2021 Jan 21;14:43-8.

13 Braakhuis A, Monnard CR, Ellis A, Rozga M. Consensus report of the academy of nutrition and dietetics: incorporating genetic testing into nutrition care. J Acad Nutr Diet. 2021 Mar;121(3):545-52.

14 Jinnette R, Narita A, Manning B, McNaughton SA, Mathers JC, Livingstone KM. Does personalized nutrition advice improve dietary intake in healthy adults? A systematic review of randomized controlled trials. Adv Nutr. 2020 Dec;12:657-69.

15 Clyne M, Schully SD, Dotson WD, Douglas MP, Gwinn M, Kolor K, et al. Horizon scanning for translational genomic research beyond bench to bedside. Genet Med. $2014 \mathrm{Jul}$; 16(7):535-8. 
16 Bauer MS, Damschroder L, Hagedorn H, Smith J, Kilbourne AM. An introduction to implementation science for the non-specialist. BMC Psychol. 2015 Sep 16;3:32.

17 Orlando LA, Sperber NR, Voils C, Nichols M, Myers RA, Wu RR, et al. Developing a common framework for evaluating the implementation of genomic medicine interventions in clinical care: the IGNITE Network's Common Measures Working Group. Genet Med. 2018 Jun;20(6):655-63.

18 Ginsburg GS, Horowitz CR, Orlando LA. What will it take to implement genomics in practice? Lessons from the IGNITE Network. Per Med. 2019 Jul;16(4):259-61.

19 Weinstein MC, Stason WB. Foundations of cost-effectiveness analysis for health and medical practices. N Engl J Med. 1977 Mar 31; 296(13):716-21.
20 Anderson JL, Heidenreich PA, Barnett PG, Creager MA, Fonarow GC, Gibbons RJ, et al. ACC/AHA statement on cost/value methodology in clinical practice guidelines and performance measures: a report of the American college of cardiology/American heart association task force on performance measures and task force on practice guidelines. J Am Coll Cardiol. 2014 Jun 3;63(21):2304-22.

21 Galekop MMJ, Uyl-de Groot CA, Ken Redekop W. A systematic review of cost-effectiveness studies of interventions with a personalized nutrition component in adults. Value Health. 2021 Mar;24(3):325-35.

22 Camp KM, Trujillo E. Position of the academy of nutrition and dietetics: nutritional genomics. J Acad Nutr Diet. 2014 Feb;114(2): 299-312.
23 Clayton EW. Ethical, legal, and social implications of genomic medicine. $\mathrm{N}$ Engl J Med. 2003 Aug 7;349(6):562-9.

24 Joly Y, Saulnier KM, Osien G, Knoppers BM. The ethical framing of personalized medicine. Curr Opin Allergy Clin Immunol. 2014 Oct; 14(5):404-8.

25 Horne JR, Vohl MC. Response to the consensus report of the academy of nutrition and dietetics: incorporating genetic testing into nutrition care. J Acad Nutr Diet. 2020 Dec; 120(12):1959-60.

26 Caudle KE, Dunnenberger HM, Freimuth RR, Peterson JF, Burlison JD, Whirl-Carrillo $\mathrm{M}$, et al. Standardizing terms for clinical pharmacogenetic test results: consensus terms from the Clinical pharmacogenetics implementation consortium (CPIC). Genet Med. 2017 Feb;19(2):215-23. 